\title{
Struktur populasi ikan cakalang hasil tangkapan pukat cincin yang didaratkan di Pelabuhan Perikanan Pantai Tumumpa Kota Manado
}

\author{
Population structure of skipjack caught with purse seine which landed in Tumumpa Coastal \\ Fishing Port, Manado City
}

\author{
Nikodemus Toatubun*, Johny WenNo dan IVOR L. LABARO \\ Program Studi Pemanfaatan Sumberdaya Perikanan, Fakultas Perikanan dan Ilmu Kelautan, \\ Universitas Sam Ratulangi, Manado 95115
}

\begin{abstract}
Skipjack (Katsuwonus pelamis) is grouped in pelagic fish. The fish mostly caught by fisherman using a purse seine. Skipjack resource utilization has been extensively practiced in Indonesia especially Manado City. Therefore, the need for information on how to structure a population of tuna caught by purse seine fishing gear, so that the information can be used for fisheries development, as well as to determine the resource management policy. This study aims to determine the population structure skipjack caught by purse seine and landed at Tumumpa Coastal Fishing Port (PPP), Manado, and to determine the growth pattern of skipjack. The results showed that the largest length composition were in the length class of 30.00 to $34.99 \mathrm{~cm}$ and the growth patterns of maximum length viable for capture $(\mathrm{L} \infty)$ was $38.03 \mathrm{~cm}$ with the coefficient $(\mathrm{K})$ of growth was $19 \%$ per year. Population structure of skipjack sample in purse seine fishery in PPP Tumumpa was divided into two sub-populations in which subpopulations with greater length caught more than the other sub-population of a smaller size.
\end{abstract}

Keywords: population structure, skipjack, catches, purse seine

\begin{abstract}
ABSTRAK
Ikan cakalang (Katsuwonus pelamis) termasuk dalam kelompok ikan pelagis. Ikan ini banyak ditangkap oleh nelayan dengan menggunakan alat tangkap pukat cincin. Pemanfaatan sumberdaya ikan cakalang sudah banyak terjadi di Indonesia, khususnya Kota Manado. Oleh sebab itu, perlu adanya informasi tentang bagaimana struktur populasi dari ikan cakalang yang tertangkap oleh alat tangkap pukat cincin, sehingga informasi tersebut dapat digunakan untuk perkembangan perikanan, maupun untuk menentukan kebijakan pengelolaan sumberdaya. Penelitian ini bertujuan untuk mengetahui struktur populasi ikan cakalang yang tertangkap oleh pukat cincin yang didaratkan di Pelabuhan Perikanan Pantai (PPP) Tumumpa Manado dan mengetahui pola pertumbuhan ikan cakalang. Hasil penelitian menunjukkan bahwa komposisi ukuran panjang ikan terbesar pada kelas 30,00-34,99 cm dengan pola pertumbuhan ikan cakalang mencapai panjang maksimum yang layak ditangkap (L $\infty$ ) 38,03 cm dengan koefisien pertumbuhan $(\mathrm{K})$ sebesar $19 \%$ per tahun. Struktur populasi dari ikan cakalang pada perikanan pukat cincin di PPP Tumumpa terbagi dalam dua sub populasi di mana sub populasi dengan ukuran panjang lebih besar tertangkap lebih banyak dibanding dengan sub populasi dengan ukuran panjang lebih kecil.
\end{abstract}

Kata-kata kunci: struktur populasi, ikan cakalang, hasil tangkapan, pukat cincin

\section{PENDAHULUAN}

Sumberdaya adalah suatu konsep yang dinamis, sehingga ada kemungkinan bahwa perubahan dalam informasi, teknologi yang relatif kelang-

\footnotetext{
*Penulis untuk penyuratan; email:

it_fpik_nikodemustoatubun@yahoo.co.id
}

sungannya dapat berakibat sesuatu yang semula dianggap tidak berguna menjadi berguna dan bernilai. Sumberdaya juga mempunyai sifat jamak dan karena itu mempunyai dimensi jumlah, kualitas, waktu dan tempat (Harahap, 2010 dalam Bahan, 2012). Sumberdaya yang dimaksudkan dalam penelitian ini yaitu ikan cakalang hasil 
tangkapan pukat cincin yang didaratkan di Pelabuhan Perikanan Pantai Tumumpa (PPP Tumumpa).

Ikan cakalang yang tersebar di seluruh perairan dunia hanya satu spesies, yaitu Katsuwonus pelamis (Jones dan Silas, 1963; Wildron dan King 1963 dalam Simbolon 2011). Ikan cakalang mempunyai nama umum skipjack atau striped tuna dan memiliki beberapa nama lokal, yaitu wadan di Jawa, cakalang atau tongkol krai di Jawa Barat dan Jakarta, buambu clorengan atau japak di Madura, kausa di Sulawesi Selatan, dan cakalang di Sulawesi Utara (Uran, 1997 dalam Simbolon, 2011).

Panjang ikan cakalang pada umur satu tahun kurang lebih $37 \mathrm{~cm}$, pada tahun kedua dapat mencapai $46 \mathrm{~cm}$, tahun ketiga $55 \mathrm{~cm}$, tahun keempat $64 \mathrm{~cm}$, tahun kelima $72 \mathrm{~cm}$, bahkan cakalang dapat sampai mencapai satu meter pada umur lebih dari 7 tahun dengan berat diperkirakan 25 kg. Pada umumnya ikan cakalang yang tertangkap berukuran panjang 40-60 $\mathrm{cm}$. Ikan cakalang yang berada pada permukaan perairan tropis adalah cakalang yang kecil (kurang dari 4 $\mathrm{kg} / \mathrm{ekor}$ ) sedangkan cakalang besar lebih dari 6,5 $\mathrm{kg} / \mathrm{ekor}$ biasanya terdapat pada perbatasan termoklin dan beradaptasi dengan perairan yang sejuk. Ikan cakalang memijah sepanjang tahun di perairan katulistiwa, antara musim semi sampai awal musim gugur di perairan sub tropis. Cakalang diperkirakan mulai memijah pada saat berumur 1 tahun dengan fekunditas telur sekitar 100.000 telur/tahun (Simbolon 2011).

Menurut Friedman (1986) dalam Prihartini (2006), jaring pukat cincin merupakan alat tangkap yang efektif untuk menangkap ikan-ikan pelagis yang berada dalam kawasan yang besar, baik di perairan pantai maupun lepas pantai. Pukat cincin adalah jenis alat tangkap yang aktif untuk menangkap ikan-ikan pelagis yang umumnya hidup membentuk kawanan dalam kelompok besar (Prihartini, 2006).

Baskoro et al (2011) menjelaskan cara pengoperasian alat tangkap pukat cincin adalah dengan melingkari dan menutupi bagian bawah jaring. Setelah jaring dilingkar dan tali kolor ditarik, maka alat ini membentuk kantong besar sehingga ikan-ikan terkurung di dalamnya dan tidak dapat meloloskan diri, sehingga ikan yang ditangkap beragam dan dalam jumlah yang bervariasi, baik ukuran, jenis maupunjumlah sehingga ikan yang tertangkap tidak terkontrol.
Sehubungan dengan uraian diatas maka salah satu informasi penting dalam pemanfaat-an sumberdaya ikan cakalang yaitu struktur populasi yang dirincikan oleh kelompok umur (cohort) tertentu. Informasi struktur populasi dari ikan cakalang yang tertangkap oleh alat tangkap tertentu, penting artinya bagi perkembangan perikanan, maupun untuk menentukan kebijakan pengelolaan sumberdaya (Leatemia, 1995).

Pemahaman tentang struktur populasi juga bertujuan untuk keberlanjutan dan efektivitas manajemen sumberdaya (Chiang et al., 2008 dalam Akbar et al., 2014). Sesuai dengan pendapat Azis (1989) dalam Aswar (2011) bahwa jika penangkapan dilakukan terus menerus untuk memenuhi permintaan komsumen tanpa adanya suatu usaha pengaturan, maka sumberdaya hayati ikan (waktu yang akan datang) dapat mengalami kelebihan tangkapan dan berakibat mengganggu kelestarian sumberdaya hayati.

Penelitian ini bertujuan untuk mengetahui komposisi ukuran panjang ikan cakalang serta mengetahui struktur populasi ikan cakalang yang tertangkap oleh pukat cincin dan yang didaratkan di PPP Tumumpa Manado.

\section{METODE PENELITIAN}

\section{Metode pengumpulan data}

Penelitian ini didasarkan pada metode deskriptif dengan pendekatan survei (Nazir, 1993). Penelitian ini mengunakan data primer berupa data ikan hasil tangkapan purse seine yang didaratkan di PPP Tumumpa. Sampel diambil berdasarkan purposive random sampling yaitu disesuaikan dengan kepentingan. Ikan sampel diukur panjang totalnya dengan cara diletakkan di atas meja milimeter blok.

\section{Analisis data}

Analisis struktur populasi dilakukan dengan metode Bhattacharya (Gayanilo, dkk., 2005). Hasil pengukuran panjang ikan dibagi dalam beberapa kelas, selanjutnya frekuensi kelas panjang dihitung distribusinya mengikuti persamaan:

$$
\text { In }\left(\mathrm{N}_{\mathrm{i}+1}\right)-\operatorname{In}\left(\mathrm{N}_{\mathrm{i}}\right)=\mathrm{a}_{\mathrm{j}}+{ }_{\text {bj. }} \mathrm{L}_{\mathrm{i}}
$$

di mana $\mathrm{N}_{\mathrm{i} \&} \mathrm{~N}_{\mathrm{i}+1}$ adalah frekuensi kelas panjang dengan ukuran yang sama, ikan sampel yang nanti akan menentukan grafik cekung, itu yang juga dapat diterjemahkan ke dalam ukuran ikan: 


$$
L_{j}=-a_{j} / b_{j}
$$

Standard deviasi $(\sigma)$ adalah

$$
\Delta_{\mathrm{j}}=\left(-\Delta \mathrm{L} / \mathrm{b}_{\mathrm{j}}\right)^{1 / 2}
$$

di mana $\Delta \mathrm{L}$ adalah nilai ukuran kelas.

$$
\mathrm{SI}=\Delta \mathrm{L}_{\mathrm{j}} / \Delta \sigma_{\mathrm{j}}
$$

di mana $\Delta \mathrm{L}_{\mathrm{i}}$ adalah perbedaan antara dan nilai tengah, dan $\Delta \sigma \mathrm{j}$ adalah perbedaan antara nilai standar deviasi yang diestimasi. Bhatthacharya dalam Gayalino, dkk. (2005) mengemukakan bahwa untuk mencari kelompok ikan dan kelompok ukuran tertentu digunakan formula:

$$
\mathrm{N}_{\mathrm{ij}}+1=\mathrm{N}_{\mathrm{i}^{-}}
$$

Penyelesaian terhadap formula ini digunakan program aplikasi Fisheries Stock Assesment Tools 2 (FISAT-2) dengan menghitung Length-Based Stock Assessment (LFSA) dengan penyelesaain melalui Electronic Length Frequency Analysis (ELEFAN).

\section{HASIL DAN PEMBAHASAN}

\section{Keadaan umum PPP Tumumpa.}

PPP Tumumpa merupakan salah satu sarana pendaratan ikan di Kota Manado yang didominasi oleh kapal dan alat tangkap pukat cincin. Jumlah armada penangkapan yang beroperasi adalah sebanyak 52 kapal dengan komposisi seperti pada Tabel 1.

Tabel 1. Variasi ukuran kapal penangkapan

\begin{tabular}{ccc}
\hline $\begin{array}{c}\text { Ukuran } \\
\text { Kapal (GT) }\end{array}$ & $\begin{array}{c}\text { Jumlah Kapal } \\
\text { (unit) }\end{array}$ & $\begin{array}{c}\text { Persentasi } \\
(\%)\end{array}$ \\
\hline 10 & 1 & 1,92 \\
18 & 1 & 1,92 \\
26 & 3 & 5,77 \\
27 & 2 & 3,85 \\
28 & 17 & 32,69 \\
29 & 24 & 46,16 \\
34 & 4 & 7,69 \\
\hline Jumlah & 52 & 100 \\
\hline
\end{tabular}

Tabel 1 tersebut menunjukkan bahwa kapal pukat cincin yang berpangkalan di PPP Tumumpa didominasi oleh kapal ukuran 29 GT yaitu sebanyak 24 unit atau 46,16\% dari jumlah total kapal. Berikutnya kapal dengan ukuran 28 GT sebanyak 17 unit atau 32,69\%.

\section{Ikan cakalang}

Panjang ikan cakalang berkisar antara 20,00-43,50 $\mathrm{cm}$. Sebaran frekuensi panjangnya disajikan pada Tabel 2.

Tabel 2. Fr ekuensi ukuran panjang ikan cakalang

\begin{tabular}{ccc}
\hline $\begin{array}{c}\text { Kelas Panjang } \\
(\mathrm{cm})\end{array}$ & $\begin{array}{c}\text { Frekuensi } \\
\text { (ekor) }\end{array}$ & $\begin{array}{c}\text { Persentase } \\
(\%)\end{array}$ \\
\hline $20,00-24,99$ & 117 & 15,39 \\
$25,00-29,99$ & 93 & 12,24 \\
$30,00-34,99$ & 334 & 43,95 \\
$35,00-39,00$ & 193 & 25,39 \\
$40,00-44,99$ & 23 & 3,02 \\
\hline Jumlah & 760 & 100 \\
\hline
\end{tabular}

Frekwensi ikan terbanyak $(43,95 \%)$ pada kelas ukuran panjang 30-34,95 cm diikuti berturut-turut kelas ukuran 35-39 cm (25,39\%), kelas 20-24,99 $\mathrm{cm}$ ( 15,39\%), kelas ukuran 25,00-29,99 (12,24\%) dan frekwensi terkecil adalah pada kelas ukuran $40,00-44,99 \mathrm{~cm}(3,02 \%)$.

\section{Struktur populasi ikan cakalang}

Hasil analisis struktur populasi ikan cakalang yang tertangkap dengan pukat cincin yang didaratkan di PPP Tumumpa terdapat dalam dua sub populasi (Gbr. 1) di mana sub populasi dengan ukuran panjang lebih besar yaitu 30,00-34,99 $\mathrm{cm}(43,95 \%)$ lebih banyak tertangkap dibanding dengan sub populasi dengan ukuran lebih kecil yaitu 20,00$24,99(15,39 \%)$.

Gambar 1 memperlihatkan bahwa ikan cakalang yang tertangkap dengan pukat cincin di Manado terdapat dalam dua sub populasi antara dua kelompok ukuran panjang dengan tingkat recruitmen (\%) atau laju pertumbuhan populasi lebih tinggi pada kelompok ikan dengan ukuran panjang yang lebih besar. 
N. Toatubun dkk.

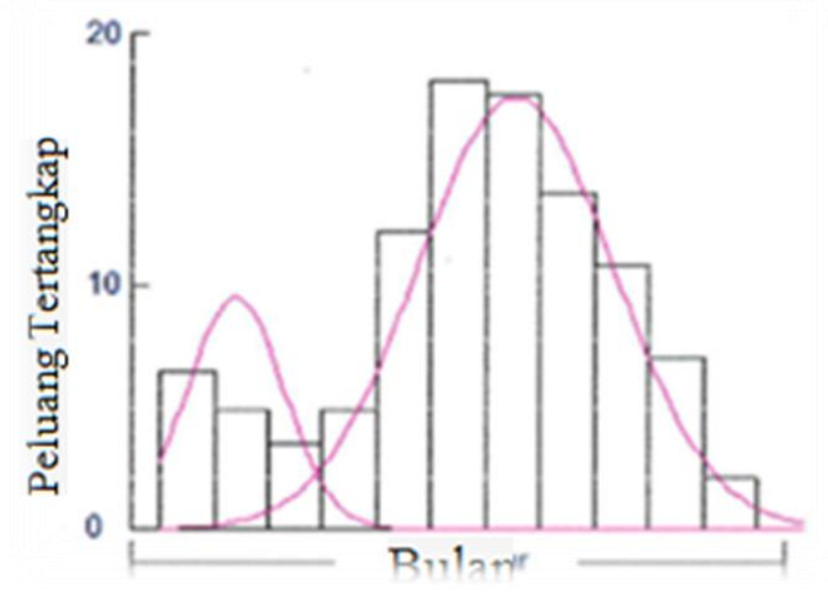

Gambar 1. Grafik struktur populasi ikan cakalang

Dilihat dari peluang tertangkapnya ikan pada beberapa ukuran yaitu L-25: $33,28 \mathrm{~cm}$, berarti bahwa ukuran ikan dengan panjang maksimal $33,28 \mathrm{~cm}$ mempunyai peluang tertangkap $25 \%$. L50: $36,38 \mathrm{~cm}$, berarti bahwa ukuran ikan dengan panjang maksimum $36,38 \mathrm{~cm}$ mempunyai peluang tertangkap 50\% dengan L-75: $36,96 \mathrm{~cm}$ berarti bahwa ukuran ikan dengan panjang maksimum $36,96 \mathrm{~cm}$ mempunyai peluang terhadap $75 \%$. Jadi semakin besar ukuran ikan, semakin besar pula peluang tertangkapnya.Keadaan ini dapat dilihat pada Gbr. 2.

Nilai koefisien pertumbuhan $(\mathrm{K})$ dari ikan cakalang sebanyak 0,19 berarti bahwa koefisien pertumbuhan jenis ikan ini cukup tinggi mencapai $19 \%$ per tahun. Panjang asimtot $\left(\mathrm{L}_{\mathrm{oo}}\right)$ ikan cakalang sesuai hasil penelitian ini yaitu $38,03 \mathrm{~cm}$ berarti bahwa ikan cakalang yang layak ditangkap hanya sampai batas ukuran maksimum $38,03 \mathrm{~cm}$. Kenyataan dari hasil panjang menunjukkan bahwa ikan yang tertangkap mencapai ukuran maksimum $43,5 \mathrm{~cm}$ yang berarti berat melebihi ukuran maksimum ikan yang layak ditangkap $\left(\mathrm{L}_{\mathrm{oo}}\right)$. Laju pertumbuhan $\left(\mathrm{K}, \mathrm{L}_{\mathrm{oo}}\right)$ digambarkan pada Gbr. 3 .

Gambar 3 juga menjelaskan bahwa pertumbuhan panjang ikan terjadi lebih cepat antara bulan Februari-Maret hingga melebihi $\mathrm{L}_{\mathrm{oo}}$ nilai-nilai pertumbuhan ini bisa saja berubah jika waktu penelitian lebih panjang dan jumlah sampel yang diambil juga lebih banyak.

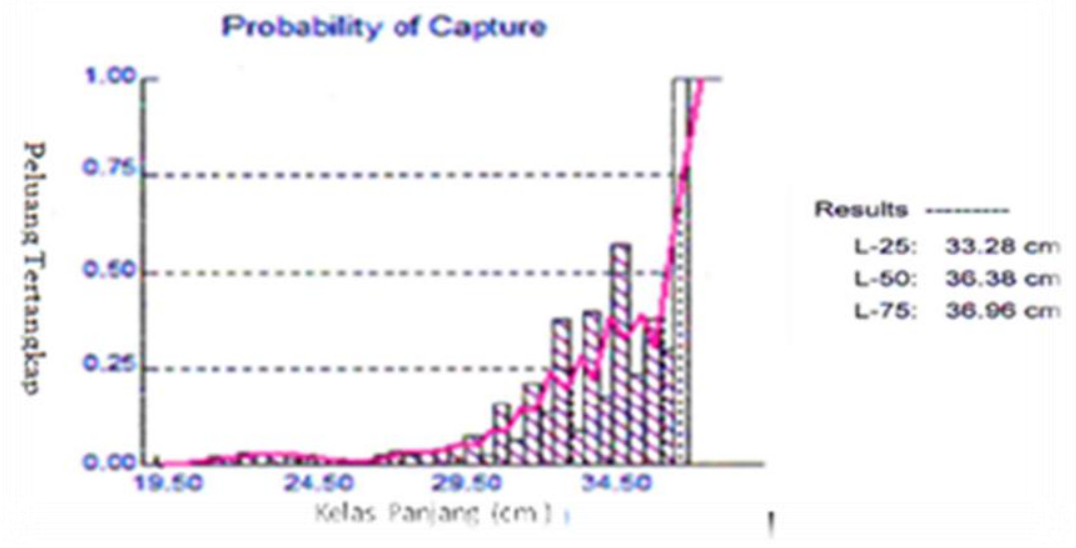

Gambar 2. Grafik probability of capture ikan cakalang 


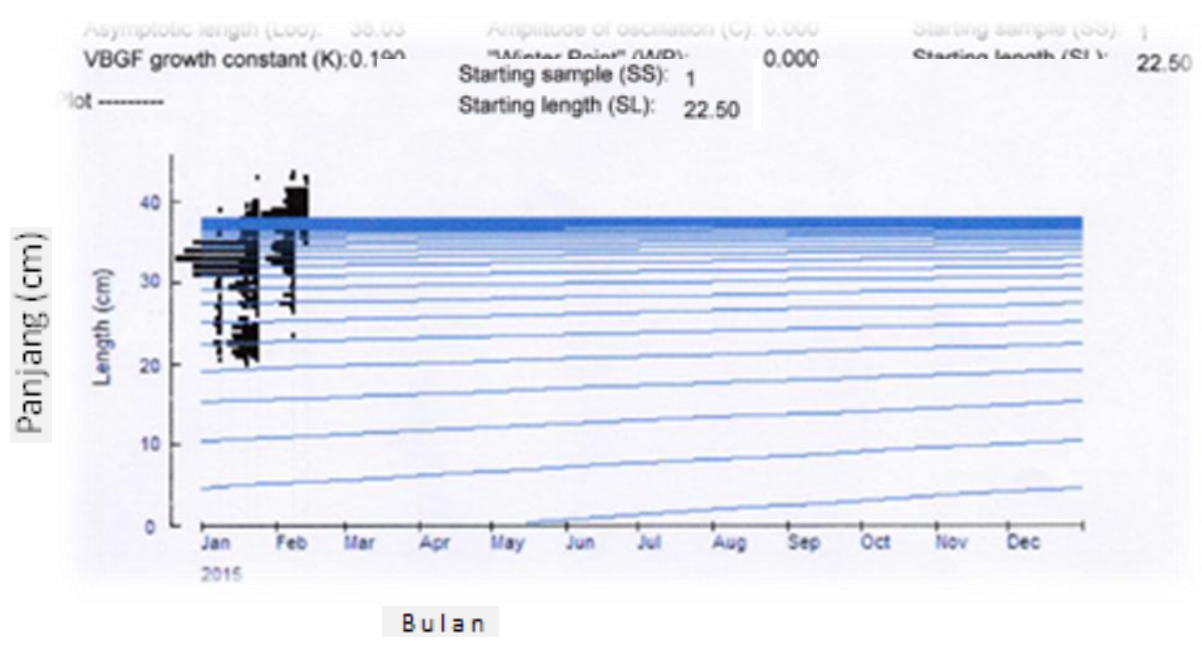

Gambar 3. Grafik koefisien pertumbuhan ikan cakalang

\section{KESIMPULAN}

Berdasarkan hasil analisis dari data ukuran panjang dan berat ikan sampel yaitu cakalang, dapat ditarik beberapa kesimpulan, antara lain:

1) Struktur populasi dari ikan sampel yaitu cakalang, dengan pukat cincin di PPP Tumumpa terbagi dalam dua sub populasi dimana sub populasi dengan ukuran panjang ikan yang lebih besar tertangkap lebih banyak dibanding dengan sub populasi pada ukuran panjang ikan yang lebih kecil.

2) Pola pertumbuhan ikan cakalang dengan panjang maksimum yang layak ditangkap $(\mathrm{L} \infty)$ $38,03 \mathrm{~cm}$ dengan koefisien pertumbuhan $(\mathrm{K})$ sebesar $19 \%$ per tahun.

\section{DAFTAR PUSTAKA}

Akbar, N., N.P. Zamani, dan H.H. Madduppa. 2014. Keragaman genetik ikan tuna sirip kuning (Thunnus albacares) dari dua populasi di Laut Maluku, Indonesia. Depik 3(1): 65-73.

Aswar, 2011. Struktur populaasi dan tekanan eksploitasi ikan tembang (Sardinella fimbriata) di perairan Laut Flores
Bulukumba. Skripsi. Fakultas Ilmu Kelautan dan Perikanan Universitas Hasannudin, Makasar.

Bahan, H.J. 2012. Analisis usaha pukat cincin kecil di Pelabuhan Perikanan Pantai Tumumpa Kota Manado. Skripsi. Fakultas Perikanan dan Ilmu Kelautan, Universitas Sam Ratulangi, Manado.

Baskoro, et al 2011. Tingkah Laku Ikan (Hubungannya dengan Ilmu dan Teknologi Perikanan Tangkap). CV. Lubuk Agung, Bandung.

Gayalino Jr., F.C., Sparre, P., dan D. Paully. 2005. FAOICLARM Stock Assessment Tools II: User's Guide. Computerized Information Series Fisheries No. 8. Food and Agriculture Organization of the United Nations, Rome.

Leatemia. R.J. 1995. Analisa struktur populasi ikan puri putih (Stelaphorus indicus Van Hasselt, 1823) yang tertangkap bagan di perairan Teluk Tuhaha. Skripsi Fakultas Perikanan Universitas Patimura, Ambon.

Simbolon, D. 2011. Bioekologi dan dinamika daerah penagkapan ikan. Depertemen Pemanfaatan Sumberdaya Perikanan Fakultas Perikanan dan Ilmu Kelautan, Institut Pertanian Bogor, Bogor.

Prihatini A., 2006. Analisis tampilan bilogi ikan layang (Decapterus sp) hasil tangkapan purse seine yang didaratkan di PPN Pekalongan. Tesis Program Pascasarjana Universitas Diponegoro, Semarang. 